\title{
Energetic ions scattered into the loss cone with observations of the Cluster satellite
}

\author{
Ying Xiong ${ }^{1,2}$, Zhigang Yuan ${ }^{1}$, and Jingfang Wang ${ }^{1}$ \\ ${ }^{1}$ School of Electronic Information, Wuhan University, Wuhan, China \\ ${ }^{2}$ School of Computer Science, Hubei University of Technology, Wuhan, China \\ Correspondence to: Zhigang Yuan (y_zgang@vip.163.com)
}

Received: 10 November 2015 - Revised: 27 January 2016 - Accepted: 4 February 2016 - Published: 17 February 2016

\begin{abstract}
In this paper, we report in situ observations by the Cluster spacecraft of energetic ions scattered into the loss cone during the inbound pass from the plasma sheet into the plasmasphere. During the inbound pass of the plasma sheet, Cluster observed the isotropy ratio of energetic ions to gradually decrease from unity and the isotropic boundary extended to lower $L$ value for higher-energy ions, implying that the field line curvature scattering mechanism is responsible for the scattered ions into the loss cone from the plasma sheet. In the outer boundary of a plasmasphere plume, Cluster 3 observed the increase of the isotropy ratio of energetic ions accompanied by enhancements of $\mathrm{Pc} 2$ waves with frequencies between the $\mathrm{He}^{+}$ion gyrofrequency and $\mathrm{O}^{+}$ion gyrofrequency estimated in the equatorial plane. Those Pc2 waves were left-hand circularly polarized and identified as electromagnetic ion cyclotron (EMIC) waves. Using the observed parameters, the calculations of the pitch angle diffusion coefficients for ring current protons demonstrate that EMIC waves could be responsible for the ions scattering and loss-cone filling. Our observations provide in situ evidence of energetic ion loss in the plasma sheet and the plasmasphere plume. Our results suggest that energetic ions scattering into the loss cone in the central plasma sheet and the outer boundary of the plasmaspheric plume are attributed to the field line curvature scattering mechanism and EMIC wave scattering mechanism, respectively.
\end{abstract}

Keywords. Magnetospheric physics (plasma waves and instabilities)

\section{Introduction}

As discrete electromagnetic emissions, electromagnetic ion cyclotron (EMIC) waves can be excited through the anisotropic energetic protons with temperature anisotropy $\left(T_{\perp}>T_{\|}\right)$(Gary et al., 1995; Horne and Thorne, 1993; Fraser and Nguyen, 2001). EMIC waves are usually observed in regions of higher cold plasma density such as, but necessarily in the plasmapause or plasmaspheric plumes (Anderson et al., 1992; Fraser and Nguyen, 2001; Chen et al., 2010; Yuan et al., 2012a; Usanova et al., 2013; Halford et al., 2015), because cold dense ions can lead to lower instability threshold for the EMIC wave excitation (Gary et al., 1995). EMIC waves, identified on the ground as Pc1-2 waves, are often excited in the magnetospheric equatorial plane (Anderson et al., 1992; Fraser et al., 2005; Engebretson et al., 2007; Yuan et al., 2012a; Sakaguchi et al., 2008). In the dayside outer magnetosphere, EMIC waves in Pc2 band can also be generated high off the equator and in the regions of the minimum of magnetic field within Shabansky orbits (Liu et al., 2012). Through the wave-particle interactions, EMIC waves can scatter ring current (RC) ions and radiation belt relativistic electrons into the loss cone, leading to loss into the atmosphere (Yahnin et al., 2006; Yahnin and Yahnina; 2007; Jordanova, et al., 2007; Sakaguchi et al., 2008; Morley et al., 2009; Yuan et al., 2010, 2012a, b, 2013; Carson et al., 2013; Li et al., 2014; Usanova et al., 2010, 2014; Wang et al., 2014). Therefore, EMIC waves may play an important role in the dynamics of the ring current and radiation belt through wave-particle interaction.

The precipitation of energetic ions from the plasma sheet or ring current is an important particle coupling process between the magnetosphere and ionosphere. The precipitation of energetic protons can significantly enhance the iono- 
spheric conductance (Galand and Richmond, 2001; Fang et al., 2007a; Yuan et al., 2014) and affect ion convection and thermospheric composition and neutral winds (Galand et al., 2001; Fang et al., 2007b). The energetic protons of the plasma sheet precipitate into the ionosphere and cause the main proton auroral oval. In addition, with the substorminduced electric field some plasma sheet protons can further be injected into the current ring region. The interaction between ring current (RC) ions and EMIC waves in the plasmapause or plasmaspheric plumes can lead to the scattering of $\mathrm{RC}$ ions into the loss cone and precipitating into the atmosphere at subauroral latitudes (Jordanova et al., 2007; Yahnin et al., 2009; Spasojević and Fuselier, 2009; Yuan et al., 2010). As a result, the low-altitude NOAA spacecraft crossing the auroral zone from high to low latitudes firstly detects an isotropic proton flux distribution and subsequently detects a drop of the proton flux within the loss cone and still a strong flux of trapped particles at lower latitudes (the anisotropic zones) (Yahnin et al., 2006; Yahnin and Yahnina; 2007; Yuan et al., 2011, 2012b, 2013). In the isotropic zones, the curved field line geometry in the magnetotail has been considered as a key mechanism causing the protons in the central plasma sheet (CPS) to be pitch angle scattered into the loss cone and subsequently precipitate in the ionosphere (e.g., Sergeev et al., 1983; Buchner and Zelenyi, 1986; Ashour-Abdalla et al., 1990; Liang et al., 2013). In the anisotropic zones, the NOAA spacecraft can observe enhancement of the precipitating ion flux at subauroral latitudes, which is a result of precipitating $\mathrm{RC}$ ions scattered into the loss cone by EMIC waves (Yahnin et al., 2002, 2006; Jordanova, et al., 2007; Yahnin and Yahnina; 2007; Yuan et al., 2012b). To better reveal the key mechanisms scattering protons into the loss cone, in situ satellite observations of simultaneous loss of energetic protons and EMIC waves are very necessary. Inside the CPS, two loss mechanisms are possibly the cause of the CPS proton loss, field line curvature scattering as well as EMIC waves. For example, Liang et al. (2014) showed simultaneous observations of EMIC waves excited in the CPS and loss of energetic protons. In the plasmapause or plasmaspheric plumes, in situ satellite observations have also shown that EMIC waves can scatter ring current protons into the loss cone (Erlandson and Ukhorskiy, 2001; Yuan et al., 2012b). However, to our knowledge, it is seldom reported that in situ satellite observation of energetic ions scattered into the loss cone during the satellite's passage from the plasma sheet into the plasmapause or plasmaspheric plumes. Thus it is likely that there are two separate regions of ion loss due to two separate loss mechanisms. It is important to identify and quantify their relative importance.

In this paper, we focus on in situ observations by the Cluster spacecraft of energetic ions scattered into the loss cone during the inbound pass from the plasma sheet into the plasmaspheric plume on 3 June 2004. In Sect. 2, after briefly describing the instrumentation (WHISPER, CIS, FGM, PEACE, EFW of the Cluster satellite), we present ob-

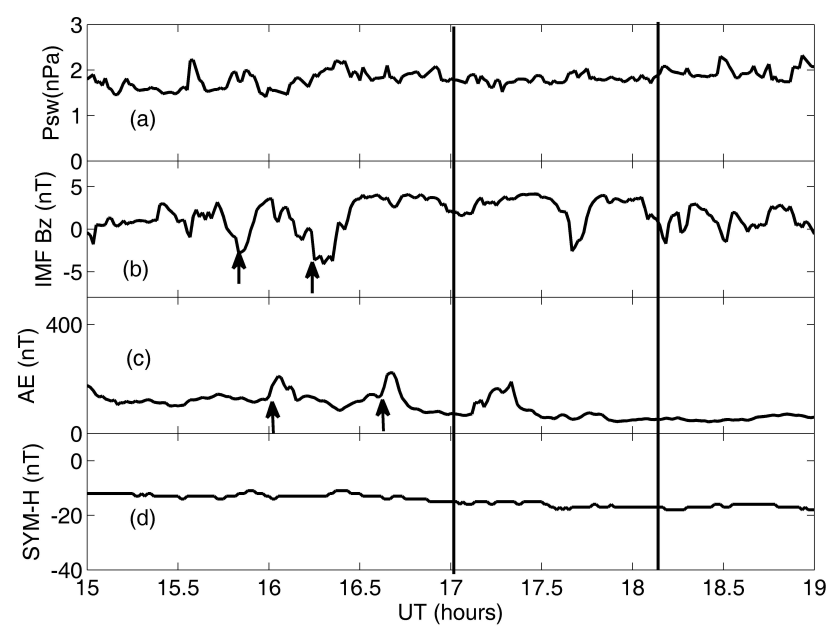

Figure 1. (a) Solar wind dynamic pressure, (b) interplanetary magnetic field (IMF) $B_{z}$ component, (c) AE index, (d) SYM$\mathrm{H}$ index, between 15:00 and 19:00 UT on 3 June 2004. The arrows in panel (b) denote two southward turnings. The arrows in panel (c) denote two sharp increases of the AE index. The interval of interest is denoted by two vertical solid lines.

servations of Cluster 3 on 3 June 2004. In Sect. 3, these results are discussed and a summary is given.

\section{Observations}

The event occurred on 3 June 2004. Figure 1 shows, from top to bottom, the solar wind dynamic pressure, IMF $B_{z}$ component, the AE index, and SYM-H index. As shown in Fig. 1a, between 15:00 and 19:00 UT the solar wind dynamic pressure kept in a moderate but stable level $(\sim 2 \mathrm{nPa})$. Within one and a half hours before the interval of interest in the present study denoted by two vertical solid lines, as shown in Fig. 1b, the IMF $B_{z}$ presents two southward turnings, implying solar-wind-magnetosphere coupling through magnetic field reconnection at subsolar magnetopause. As a result, the energetic ions/electrons in the magnetotail plasma sheet can be injected into inner magnetosphere and high-latitude ionosphere, which leads to two sharp enhancements of the AE index denoted by the arrows in Fig. 1c. As shown in Fig. 1d, the SYM-H stayed greater than $-20 \mathrm{nT}$, implying weak activity of the ring current during the interval.

We use data from instruments onboard the Cluster spacecraft to conduct the study. Electron density data are derived by identifying the electron plasma frequency in the frequency range of $2-80 \mathrm{kHz}$ measured by the Waves of High frequency and Sounder for Probing Electron density by Relaxation (WHISPER) instrument (Décréau et al., 2001). In addition, the spacecraft potential data from the Electric Field and Wave (EFW) instrument (Gustafsson et al., 2001) are used as a proxy of the total electron density (Pedersen et al., 2001). The Hot Ion Analyzer (HIA) sensor of the Cluster Ion Spectrometry (CIS) instrument measures the 3-D dis- 


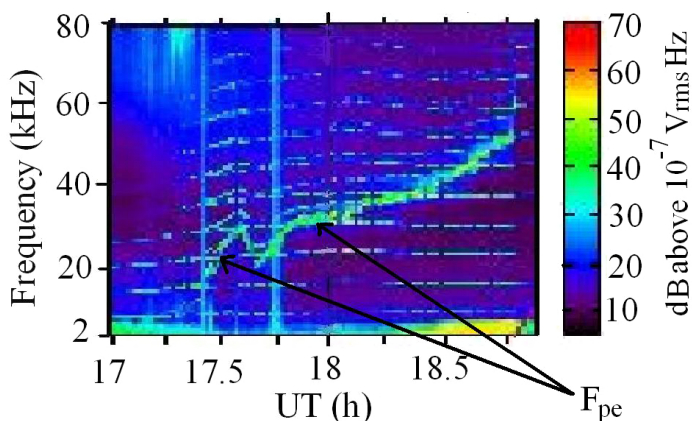

Figure 2. Frequency-time spectrogram measured by the WHISPER instrument onboard C3 between 17:00 and 18:50 UT on 3 June 2004. The plasma frequency $\left(F_{\mathrm{pe}}\right)$ is indicated by the black arrows.

tribution functions of ions between $5 \mathrm{eV} \mathrm{q}^{-1}$ and $32 \mathrm{keV} \mathrm{q}^{-1}$ without mass discrimination in one spacecraft spin $(4 \mathrm{~s})$ time resolution (Rème et al., 2001). Thus, measurements of the HIA cover a substantial part of the ring current energy range (Williams, 1987). The high-resolution magnetic field data with a $22 \mathrm{~Hz}$ sampling frequency are provided by a fluxgate magnetometer (FGM) (Balogh et al., 2001). Thermal $(<25 \mathrm{keV})$ electron distribution data are provided by the Plasma Electron and Current Experiment (PEACE) instrument (Johnstone et al., 1997).

Figure 2 displays frequency-time electric field spectrograms from the C3 WHISPER instruments between 17:00 and 18:50 UT on 3 June 2004. As denoted by the black arrows in Fig. 2, there is an obvious plasma frequency $\left(F_{\mathrm{pe}}\right)$ trace, which is used to derive the electron density. In order to better demonstrate the plasmaspheric plume crossing by Cluster 3, we plot the electron number density along the trajectories of Cluster 3 projected along the magnetic field lines onto the equatorial plane in the GSM coordinates with the TS-05 model (Tsyganenko and Sitnov, 2005). As shown in Fig. 3, it is easy to see that Cluster 3 firstly encountered the plasmaspheric plume and then entered into the main plasmasphere.

An overview of Cluster 3 data during the time interval from 17:00 to 18:12 UT on 3 June 2004 is shown in Fig. 4, including the spacecraft potential, electron number density, electron spectrogram, ion spectrogram and energy flux, the perturbed magnetic field, and power spectral density of one of the perpendicular components of the perturbed magnetic field $\left(\Delta B_{\mathrm{t} 2}\right)$ in the field-aligned coordinate system. During the interval denoted by two red vertical solid lines in Fig. 4, i.e., between 17:22 and 18:12 UT on 3 June 2004, Fig. 4a presents a high spacecraft potential observed by EFW on Cluster 3, indicating that Cluster 3 observed a high total electron density and passed through a plasmaspheric plume (Pedersen et al., 2001). Prior to 17:29 UT, the trace of electron plasma frequency $\left(F_{\mathrm{pe}}\right)$ is not clear on the frequencytime electric field spectrogram measured by the WHISPER instrument shown in Fig. 2. Thus it is difficult to use the
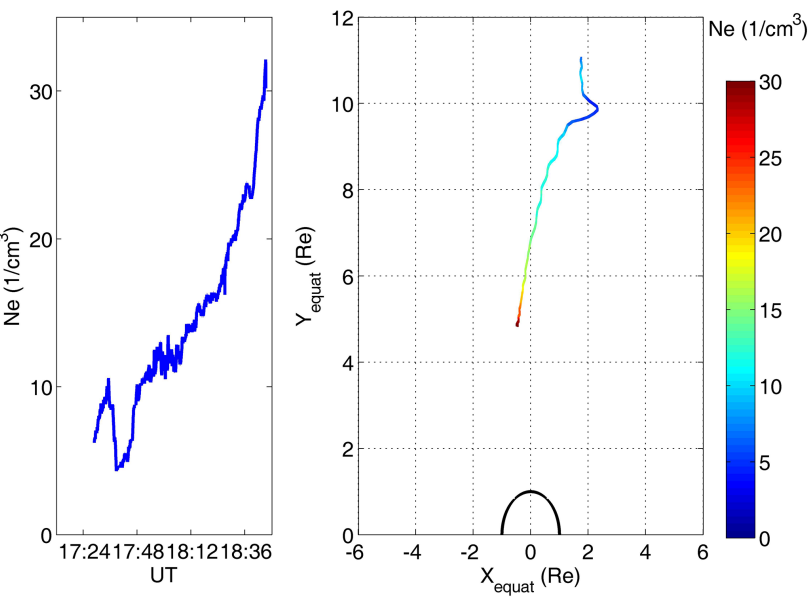

Figure 3. Electron density observed by the WHISPER instrument of C3 during between 17:12 and 18:48 UT on 3 June 2004. Left panel: electron density vs. UT. Right panel: electron density plotted along the trajectories of $\mathrm{C} 3$ projected along the magnetic field lines onto the equatorial plane in a co-rotating geocentric solar magnetospheric (GSM) frame of reference.

$F_{\mathrm{pe}}$ to determine the cold plasma density or the location of the plasmapause. We instead use the spacecraft potential observed by the EFW instrument to indicate the outer boundary of the plasmasphere plume during this time interval. The outer boundary of the plasmasphere plume is identified by an increase of the spacecraft potential value shown in Fig. 4a at 17:22 UT. As the spacecraft potential-derived electron density has some uncertainties (Scudder et al., 2000), we only use the spacecraft potential to identify the outer boundary of the plasmasphere plume, as shown in Fig. 4b. In this paper we derive the electron density value using the WHISPER instrument. As marked by the right red vertical solid line of Fig. 4, the inner boundary of the plume is well identified by the decrease of the electron density to the background level at 17:39 UT. Thereafter, as denoted by the yellow vertical solid line, Fig. 4b presents that the electron density starts to increase at 17:46 UT, meaning that Cluster 3 entered into the outer boundary of the main plasmasphere. Panels (c)-(d) show PEACE electron energy-time spectrogram at pitch angle of 180 and $90^{\circ}$ respectively. Between 17:00 and 17:20 UT, as denoted by green vertical solid lines in Fig. 4, the Cluster C3, observed the strong electron flux with energies of $0.1-6 \mathrm{keV}$, implying a passage of the plasma sheet or the auroral zone.

As shown in Fig. 4e, in the plasma sheet the HIA observed ions of several keV, i.e., plasma sheet ions. In addition, strong fluxes of high-energy (>10 keV) trapped ions were observed at lower $L$ values, indicating the presence of ring current ions (Vallat et al., 2004). After 18:00 UT the HIA data suffered a strong background due to penetrating particles from the radiation belts, appearing as a high counting rate in all energies (Dandouras et al., 2009). Panel (f) displays ion flux 


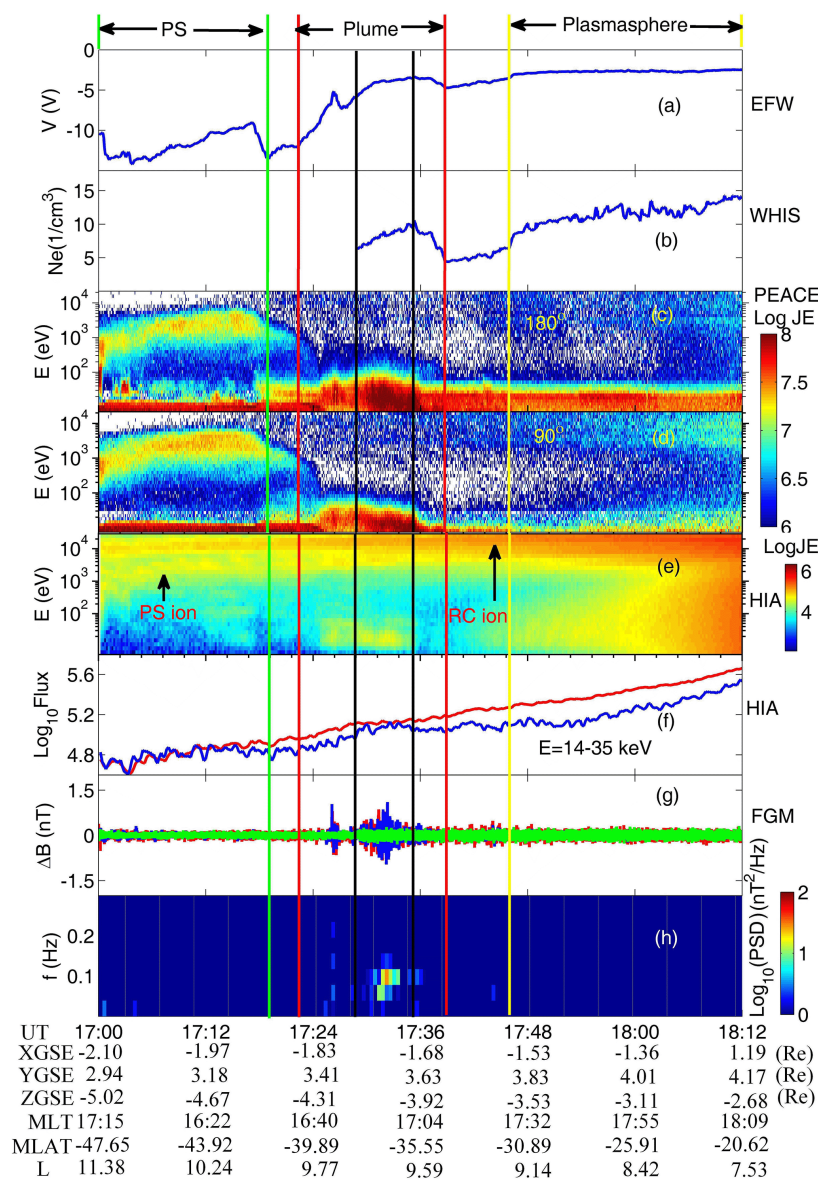

Figure 4. Overview of data from Cluster 3 between 17:00 and 18:12 UT on 3 June 2004. Panel (a): negative of the spacecraft potential measured by the EFW experiment. Panel (b): electron density derived from the electron plasma frequency detected by the WHISPER instrument. Panels (c-d): PEACE electron energy-time spectrogram in particle energy flux units $(\mathrm{keV}$ $\mathrm{cm}^{-2} \mathrm{~s}^{-1} \mathrm{sr}^{-1} \mathrm{keV}^{-1}$ ) at pitch angles of 180 and $90^{\circ}$, respectively. Panel (e): HIA omnidirectional energy-time spectrogram in energy particle flux units $\left(\mathrm{keV} \mathrm{cm}^{-2} \mathrm{~s}^{-1} \mathrm{sr}^{-1} \mathrm{keV}^{-1}\right)$. Panel (f): ion flux with energies of $14 \mathrm{keV}-35 \mathrm{keV}$ measured by HIA. Ion fluxes with local pitch angles of $80-90$ and $170-180^{\circ}$ are denoted by red and blue lines, respectively. Panel (g): disturbed magnetic field in the field-aligned coordinate system. The two perpendicular components $\left(\Delta B_{\mathrm{t} 1}\right.$ and $\left.\Delta B_{\mathrm{t} 2}\right)$ and the field-aligned component $\left(\Delta B_{\mathrm{FA}}\right)$ of the perturbed magnetic field in the field-aligned coordinate system are denoted by red, blue, and green solid lines, respectively. Panel (h): power spectral density (PSD) of the $\Delta B_{\mathrm{t} 2}$ component of the disturbed magnetic field. Black vertical solid lines denote the time interval of enhanced PSD for Pc2 waves.

with energies of 14-35 keV measured by the HIA with local pitch angle of $80-90$ and $170-180^{\circ}$ denoted by the red and blue lines, respectively. Since the loss cone angle at the location Cluster 3 is about $4^{\circ}$ with the ambient magnetic field observed by the Cluster 3 (not shown here), observed ions with pitch angle of $80-90^{\circ}$ are out of the local loss cone and considered as trapped ions while those with pitch angle of $170-180^{\circ}$ include trapped and precipitating ions.

As denoted by the red line in Fig. 4f, the increase of trapped ion flux with energies of $14-35 \mathrm{keV}$ implied enhancements of RC density. In the plasma sheet, the ion flux with energies of $14-35 \mathrm{keV}$ for the pitch angles of $80-90^{\circ}$ is almost same as that for the pitch angels of $170-180^{\circ}$, implying an isotropic distribution. To be noted, during the interval denoted by two black vertical solid lines in Fig. 4, the ion flux with local pitch angles of $170-180^{\circ}$ denoted by the blue lines in Fig. 4h sharply increased so that the pitch angle distribution became more isotropic. The isotropic enhancement of ions with energies of $14-35 \mathrm{keV}$ should be attributed to RC ions scattered into the loss cone by EMIC waves, which will be discussed as follows.

With a $25.6 \mathrm{~s}$ running time window, the high-resolution magnetic fields observed by the FGM are separated into the averaged magnetic field and perturbed magnetic field (Yuan et al., 2012a). The perturbed magnetic field is used to extract the Pc2 waves. In order to better study characteristics of Pc2 waves observed by Cluster 3, the perturbed magnetic field in GSE coordinates is transformed into a field-aligned coordinate system. As shown in Fig. 4g, two perpendicular components $\left(\Delta B_{\mathrm{t} 1}\right.$ and $\left.\Delta B_{\mathrm{t} 2}\right)$ and the field-aligned component $\left(\triangle B_{\mathrm{FA}}\right)$ of the perturbed magnetic field are denoted by red, blue, and green solid lines respectively. During the interval denoted by two black vertical solid lines in Fig. 4g, the amplitude of the perturbed magnetic field increases. Since the transverse component $\Delta B_{\mathrm{t} 2}$ of the perturbed magnetic field is much stronger than the $\Delta B_{\mathrm{FA}}$ component, the direction of the perturbed magnetic field should be nearly in the plane perpendicular to the background magnetic field. The strongest component of the perturbed magnetic field, $\Delta B_{\mathrm{t} 2}$, is used to obtain the power spectral density through fast Fourier transforms (FFTs), which is shown in Fig. 4h. During the interval denoted by the two black vertical solid lines in Fig. $4 \mathrm{~h}$, the frequency of the perturbed magnetic field is about $0.1 \mathrm{~Hz}$, i.e., in the Pc2 band.

\section{Discussion and conclusion}

In order to better show the wave power and polarization characteristics of the Pc2 waves observed by Cluster 3, a wavelet analysis is used to obtain the wave power for leftand right-hand polarized components $\left(B_{1}=\Delta B_{\mathrm{t} 1}-i \Delta B_{\mathrm{t} 2}\right.$ and $B_{\mathrm{r}}=\Delta B_{\mathrm{t} 1}+i \Delta B_{\mathrm{t} 2}$ ) (Volwerk et al., 2008). Figure 5 presents the wavelet spectrograms for Cluster 3 during the interval of 17:00-17:48 UT. Those local $\mathrm{O}^{+}$ion gyrofrequency $\left(f_{\mathrm{O}}+\right.$ Loc $)$ is derived from the background magnetic field, which is the average magnetic field mentioned above. On the other hand, the ion gyrofrequencies in the equatorial plane $\left(f_{\mathrm{O}+\text { eq }}, f_{\mathrm{He}+\text { eq }}\right)$, which is the projection of Cluster trajectories along the magnetic field, can be calculated with the TS-05 model (Tsyganenko and Sitnov, 2005). As shown in Fig. 5a and b, the Pc2 waves, circled in black, are between 


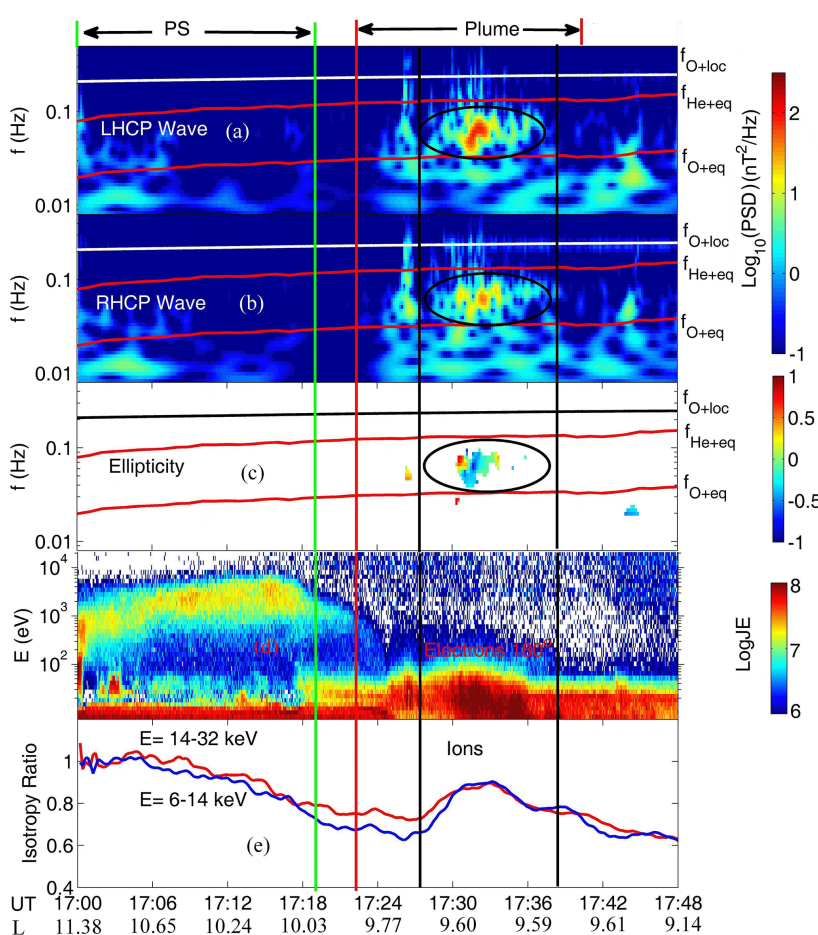

Figure 5. Wavelet power spectrum of the perturbed magnetic field, electron energy-time spectrogram in particle energy flux units $\left(\mathrm{keV} \mathrm{cm}^{-2} \mathrm{~s}^{-1} \mathrm{sr}^{-1} \mathrm{keV}^{-1}\right)$, isotropy ratio of ions with energies of $6-14 \mathrm{keV}$ and $14-32 \mathrm{keV}$ between 17:00 and 17:48 UT on 3 June 2004. Panels (a-c), from top to bottom, the power spectrum of LHCP, RHCP components and the ellipticity of the transverse waves in the field-aligned coordinates are plotted, respectively. Periods of enhanced EMIC wave power are circled in black. Panel (d): PEACE electron energy-time spectrogram in particle energy flux units at pitch angles of $180^{\circ}$. Panel (e): isotropy ratio of ions with energies of 6-14 keV (blue lines) and 14-32 keV (red lines) measured by HIA. Two black vertical lines denoted the enhancements of ion isotropy ratio in the outer boundary of the plasmaspheric plume.

the $\mathrm{O}^{+}$ion gyrofrequency $\left(f_{\mathrm{O}+\text { eq }}\right)$ and the $\mathrm{He}^{+}$ion gyrofrequency $\left(f_{\mathrm{He}}+\mathrm{eq}\right)$ in the equatorial plane, i.e., in frequency range for $\mathrm{He}^{+}$ion cyclotron waves in the equatorial plane, in agreement with the previous observations and theory of EMIC waves (Erlandson and Ukhorskiy, 2001; Morley et al., 2009; Yuan et al., 2010, 2012a; Young et al., 1981). As shown in Fig. 5c, the ellipticity of the transverse waves $(-1,0,+1$ are for left-hand circular polarization (LHCP), linear polarization, and right-hand circular polarization (RHCP), respectively. Here the ellipticity is only shown when the PSD of LHCP or RHCP waves is larger than $5 \mathrm{nT}^{2} \mathrm{~Hz}^{-1}$ ) demonstrates that the wave packets are mainly left-hand polarized, which is an important characteristic for EMIC waves (Anderson et al., 1992). Therefore, those observed left-hand circularly polarized Pc2 waves, with frequencies between the $\mathrm{He}^{+}$ ion gyrofrequency and $\mathrm{O}^{+}$ion gyrofrequency in the equato- rial plane, can be identified as EMIC waves originating from the equatorial plane and propagating to the site of Cluster 3 .

Within one and a half hours before the EMIC wave events, as shown in Fig. 1, there are three sharp enhancements of the $\mathrm{AE}$ index, indicating that energetic ions/electrons in the magnetotail plasma sheet could be injected into inner magnetosphere and high-latitude ionosphere. Those energetic ions and electrons could be injected at local midnight and drift toward the dayside. Due to drift shell splitting, ring current ion fluxes with an anisotropic pitch angle distribution are enhanced in the afternoon sector (Sibeck et al., 1987). With density enhancements of cold ions, the anisotropic RC proton distributions can become unstable so as to easily excite EMIC waves (Gary et al., 1995). Therefore, EMIC waves in the inner magnetosphere may occur in the region of overlap between the plasmasphere and ring currents (Fraser and Nguyen, 2001; Yuan et al., 2010, 2012a; Usanova et al., 2013), and in regions of high cold plasma density (Yahnin et al., 2002; Halford et al., 2015). In addition, the density structure with the negative gradient of radial electron densities at the plasmapause or plasmaspheric plumes can guide EMIC waves, leading to a small wave normal angle and an order of enhancement of the wave strength (Chen et al., 2009). Therefore, EMIC waves are frequently observed in the outer boundary of the plasmasphere or detached plasmaspheric plumes (Erlandson and Ukhorskiy, 2001; Fraser and Nguyen, 2001; Jordanova, et al., 2007; Yuan et al., 2012a, 2013). In fact, Figs. 4 and 5 show that EMIC waves are observed in the outer boundary of the plasmaspheric plume with occurrence of RC ions. Since Fig. 1d shows a weak geomagnetic activity during the interval, energetic ions in the magnetotail plasma sheet should only be injected into the region of higher $L$ value. Under a weak geomagnetic activity, the plasmapause can extend to a higher $L$ value. As a result, EMIC waves are observed in the outer boundary of the plasmaspheric plume at a high $L$ value $(L \sim 9.6)$.

In order to better study energetic ions scattered into the loss cone, we estimate the isotropy ratio of the energetic ion distribution $\left(J_{170-180^{\circ}} / J_{80}-90^{\circ}\right) . J_{170-180^{\circ}}$ and $J_{80-90^{\circ}}$ represent ion fluxes with local pitch angles of 80-90 and 170$180^{\circ}$, respectively. As shown in Fig. 5, during the outbound pass of the plasma sheet where the ions/electron flux with energies of several $\mathrm{keV}$ enhanced, Cluster 3 observed that the isotropy ratios of ions with energies of 6-14 and 14-32 keV gradually decreased from unity and the isotropic boundary extended to lower $L$ value for higher-energy ions. Since under normal magnetospheric topology both the curvature radius of the magnetic field line and the equatorial magnetic field strength increase toward the Earth, the field line curvature scattering will lead to a normal-type dispersion feature: the isotropic boundary extends toward lower $L$ value for higher-energy ions (Liang et al., 2014). Therefore, in the plasma sheet, field line curvature scattering mechanism should be responsible for our observed normal-type dispersion feature of precipitating ions (the isotropic boundary ex- 
tends to lower $L$ value for higher-energy ions) (Sergeev et al., 1983; Buchner and Zelenyi, 1986; Ashour-Abdalla et al., 1990, Liang et al., 2013). To be noted, during the interval denoted by two black vertical solid lines in Fig. 5e, isotropy ratios of energetic ions for both 6-14 and 14-32 keV enhanced during the activity of EMIC waves. Therefore, the isotropic enhancement of energetic ions during the interval denoted by two black vertical solid lines in Fig. 5e should be attributed to RC ions scattered into the loss cone by EMIC waves.

In order to further confirm that the EMIC waves can lead to the enhancement of the energetic ion isotropy denoted by two black vertical solid lines in Fig. 5e, we calculate the bounce-averaged pitch angle diffusion coefficients for energetic protons using the quasi-linear approach with observations of Cluster 3 (Summers et al., 2007). As shown in Fig. 6a, a Gaussian fitting (red solid line) was applied to the dominant frequency band of observed EMIC waves between 17:31:30 and 17:31:40 UT on 3 June 2004. As denoted by two black vertical lines in Fig. 6a, the band of $\mathrm{Pc} 2$ waves is between the $\mathrm{O}^{+}$ion gyrofrequency $\left(f_{\mathrm{O}+\mathrm{eq}}\right)$ and the $\mathrm{He}^{+}$ion gyrofrequency $\left(f_{\mathrm{He}}+\right.$ eq $)$ in the equatorial plane, implying $\mathrm{He}^{+}$band EMIC waves. The TS-05 model is used to calculate the magnetic field of the equatorial projection of Cluster trajectories along the magnetic field. A retarding potential analyzer (RPA) equipped on the CODIF can measure ion species $\left(\mathrm{H}^{+}, \mathrm{He}^{++}, \mathrm{He}^{+}\right.$, and $\left.\mathrm{O}^{+}\right)$in the energy range of $\sim 0.7-25 \mathrm{eV} \mathrm{q}^{-1}$ with respect to the spacecraft potential, covering the plasmaspheric energy domain (Rème et al., 2001). Therefore, the CODIF instrument in the RPA mode is better to detect plasmaspheric ions (Darrouzet et al., 2008). Unfortunately the RPA mode of the CODIF instrument was not active during the time interval studied here. Therefore, relevant cold ion compositions of $\left[\mathrm{H}^{+}\right]:\left[\mathrm{He}^{+}\right]:\left[\mathrm{O}^{+}\right]=82: 15: 3$ is assumed (Grew et al., 2007). The plasma density is $10 \mathrm{~cm}^{-3}$ with observations of Cluster 3. We assume that both the background electron density and EMIC wave spectral intensity are constant along a field line. Given an EMIC wave propagating parallel or antiparallel to the background magnetic field, with equation 30 from Summers et al. (2007), the bounce-averaged pitch angle diffusion coefficients $\langle D \alpha \alpha\rangle$ can be calculated by a standard numerical quadrature technique. It is useful to compare the magnitudes of the pitch angle diffusion coefficients $\langle D \alpha \alpha\rangle$ for protons scattered by EMIC waves with the "strong" pitch-angle diffusion rate $D_{\mathrm{SD}}$ as defined by Kennel and Petschek (1966). $\langle D \alpha \alpha\rangle>>D_{\mathrm{SD}}$ indicates a strong diffusion, while $\langle D \alpha \alpha\rangle\left\langle D_{\mathrm{SD}}\right.$ indicates a weak diffusion. For a small equatorial loss cone, the result can be expressed written as (Eq. (27) of Summers and Thorne, 2003):

$D_{\mathrm{SD}} \approx \frac{9.66}{L^{4}}\left[\frac{4 L}{4 L-3}\right]^{\frac{1}{2}} \frac{[E(E+2)]^{\frac{1}{2}}}{(E+1)}\left(s^{-1}\right)$

In Eq. (1), $L$ and $E$ denote the $L$ values and normalized kinetic energy to proton rest energy.
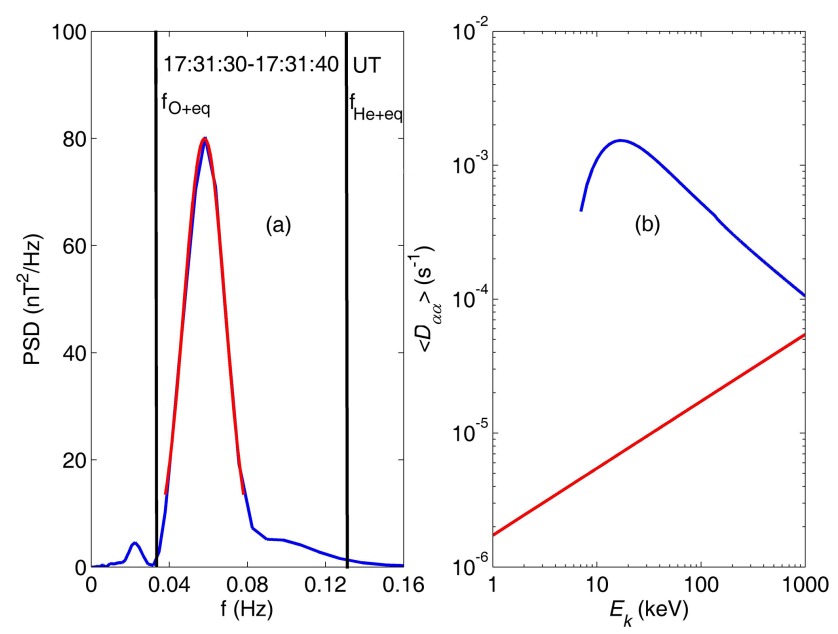

Figure 6. (a) A Gaussian fitting (red solid line) was applied to the dominant frequency band of the observed EMIC waves between 17:31:30 and 17:31:40 UT on 3 June 2004. Two black vertical lines denote the $\mathrm{He}^{+}$and $\mathrm{O}^{+}$ion gyrofrequencies at the equatorial plane, respectively. (b) Bounce-averaged pitch angle diffusion rate near the equatorial loss cone (Blue lines) for EMIC waves resonating with ring current ions for the wave shown in (a). The red curve represents the rate of strong pitch diffusion given by Eq. (1).

Figure $6 \mathrm{~b}$ shows the bounce-averaged pitch angle diffusion coefficients near the equatorial loss cone angle for protons. In addition, the red curve represents the rate of strong pitch diffusion $D_{\mathrm{SD}}$ given by Eq. (1) at $L=9.6$. As shown in Fig. $6,\langle D \alpha \alpha\rangle>>D_{\mathrm{SD}}$ is met in the energy range of $4 \mathrm{keV}-$ $1 \mathrm{MeV}$, indicating that the EMIC waves can resonate with protons at energies from $4 \mathrm{keV}-1 \mathrm{MeV}$ and strongly scatter those protons into the loss cone. Therefore, observed EMIC waves can lead to the isotropization of energetic ions denoted by two black vertical solid lines in Fig. 5e.

In summary, with observations of the Cluster spacecraft, we report in situ evidence of energetic ions scattered into the loss cone during the inbound pass from the plasma sheet into the plasmasphere. During the outbound pass of the plasma sheet, Cluster observed the isotropy ratio of energetic ions to gradually decrease from unity and the isotropic boundary extended to lower $L$ value for higher-energy ions, indicating that field line curvature scattering mechanism is responsible for the scattered ions into the loss cone in the plasma sheet. In the outer boundary of the plasmaspheric plume, Cluster 3 observed the increase of the isotropy ratio of energetic ions accompanied by enhancements of Pc2 waves. Through the analysis of the power spectral density and polarization, those Pc2 waves were left-hand circularly polarized and identified as $\mathrm{He}^{+}$band EMIC waves. With observed parameters, the calculations of the pitch angle diffusion coefficients for ring current protons demonstrate that EMIC waves could be responsible for the ions scattering and loss-cone filling. Our results suggest that energetic ions scattering into the loss cone 
in the central plasma sheet and the outer boundary of the plasmaspheric plume are attributed to the field line curvature scattering mechanism and EMIC wave scattering mechanism, respectively.

Acknowledgements. We thank the Cluster teams and Cluster Active Archive (CAA) for the high-quality data and successful operation. The SYM-H and AE index data are provided by the World Data Center for geomagnetism at Kyoto University at http://wdc. kugi.kyoto-u.ac.jp/wdc/Sec3.html. The data of the GSM IMF Bz and Solar wind dynamic pressure are from the Coordinated Data Analysis Web (CDAWeb) at http://cdaweb.gsfc.nasa.gov/cdaweb/ istp_public/. This research is supported by the National Natural Science Foundation of China (41174140, 41204112, 41374168, 4152106), the Keygrant Project of Chinese Ministry of Education (2042015kf0169), and Program for New Century Excellent Talents in University (NCET-13-0446).

The topical editor, E. Roussos, thanks two anonymous referees for help in evaluating this paper.

\section{References}

Anderson, B. J., Erlandson, R. E., and Zanetti, L. J.: A statistical study of Pc1-2 magnetic pulsations in the equatorial magnetosphere 2. Wave properties, J. Geophys. Res., 97, 3089-3101, 1992.

Ashour-Abdalla, M., Berchem, J., Buchner, J., and Zelenyi, L. M.: Chaotic scattering and acceleration of ions in Earth's magnetotail, Geophys. Res. Lett., 17, 2317-2320, doi:10.1029/GL017i013p02317, 1990.

Balogh, A., Carr, C. M., Acuña, M. H., Dunlop, M. W., Beek, T. J., Brown, P., Fornacon, K.-H., Georgescu, E., Glassmeier, K.H., Harris, J., Musmann, G., Oddy, T., and Schwingenschuh, K.: The Cluster Magnetic Field Investigation: overview of in-flight performance and initial results, Ann. Geophys., 19, 1207-1217, doi:10.5194/angeo-19-1207-2001, 2001.

Buchner, I. and Zelenyi, L. M.: Deterministic chaos in the dynamics of charged particle near amagnetic field reversal, Phys. Lett. A, 118, 395-399, 1986.

Carson, B. R., Rodger, C. J., and Clilverd, M. A.: POES satellite observations of EMIC-wave driven relativistic electron precipitation during 1998-2010, J. Geophys. Res.-Space, 118, 232-243, doi:10.1029/2012JA017998, 2013.

Chen, L., Thorne, R. M., and Horne, R. B.: Simulation of EMIC wave excitation in a model magnetosphere including structured high-density plumes, J. Geophys. Res., 114, A07221, doi:10.1029/2009JA014204, 2009.

Chen, L., Thorne, R. M., Jordanova, V. K., Wang, C.-P., Gkioulidou, M., Lyons, L., and Horne, R. B.: Global simulation of EMIC wave excitation during the 21 April 2001 storm from coupled RCM-RAMHOTRAY modeling, J. Geophys. Res., 115, A07209, doi:10.1029/2009JA015075, 2010.

Dandouras, I., Cao, J., and Vallat, C.: Energetic ion dynamics of the inner magnetosphere revealed in coordinated ClusterDouble Star observations, J. Geophys. Res., 114, A01S90, doi:10.1029/2007JA012757, 2009.
Darrouzet, F., De Keyser, J., Décréau, P. M. E., El LemdaniMazouz, F., and Vallières, X.: Statistical analysis of plasmaspheric plumes with Cluster/WHISPER observations, Ann. Geophys., 26, 2403-2417, doi:10.5194/angeo-26-2403-2008, 2008.

Décréau, P. M. E., Fergeau, P., Krasnoselskikh, V., Le Guirriec, E., Lévêque, M., Martin, Ph., Randriamboarison, O., Rauch, J. L., Sené, F. X., Séran, H. C., Trotignon, J. G., Canu, P., Cornilleau, N., de Féraudy, H., Alleyne, H., Yearby, K., Mögensen, P. B., Gustafsson, G., André, M., Gurnett, D. C., Darrouzet, F., Lemaire, J., Harvey, C. C., Travnicek, P., and Whisper experimenters (Table 1): Early results from the Whisper instrument on Cluster: an overview, Ann. Geophys., 19, 1241-1258, doi:10.5194/angeo-19-1241-2001, 2001.

Engebretson, M. J., Keiling, A., Fornacon, K.-H., Cattell, C. A., Johnson, J. R., Posch, J. L., Quick, S. R., Glassmeier, K.-H., Parks, G. K., and Rème H.: Cluster observation of Pc 1-2 waves and associated ion distributions during the October and November 2003 magnetic storms, Planet. Space Sci., 55, 829-848, doi:10.1016/j.pss.2006.03.015, 2007.

Erlandson, R. E. and Ukhorskiy, A.: Observations of electromagnetic ion cyclotron waves during geomagnetic storms: wave occurrence and pitch angle scattering, J. Geophys. Res., 106, 3883 3895. 2001.

Fang, X., Liemohn, M. W., Kozyra, J. U., and Evans, D. S.: Global 30-240 keV proton precipitation in the 17-18 April 2002 geomagnetic storms: 2. Conductances and beam spreading, J. Geophys. Res., 112, A05302, doi:10.1029/2006JA012113, 2007a.

Fang, X., Ridley, A. J., Liemohn, M. W., Kozyra, J. U., and Evans, D. S.: Global 30-240 keV proton precipitation in the 17-18 April 2002 geomagnetic storms: 3. Impact on the ionosphere and thermosphere, J. Geophys. Res., 112, A07310, doi:10.1029/2006JA012144, 2007b.

Fraser, B. J. and Nguyen, T. S.: Is the plasmaspause a preferred source region of electromagnetic ion cyclotron waves in the magnetosphere?, J. Atmos. Terr. Phys., 63, 1225-1247, 2001.

Fraser, B. J., Singer, H. J., Adrian, M. L., and Gallagher, D. L.: The relationship between plasma density structure and EMIC waves at geosynchronous orbit, in: Inner Magnetosphere Interactions: New Perspectives From Imaging, Geophys. Monogr. Ser., edited by: Burch, J. L., Schulz, M., and Spence, H., 159, 55-70, AGU, Washington, D.C., USA. doi:10.1029/159GM04, 2005.

Galand, M., Fuller-Rowell, T. J., and Codrescu, M. V.: Response of the upper atmosphere to auroral protons, J. Geophys. Res., 106, 127-139, 2001.

Galand, M. and Richmond, A. D.: Ionospheric electrical conductances produced by auroral proton precipitation, J. Geophys. Res., 106, 117-125, doi:10.1029/1999JA002001, 2001.

Gary, S. P., Thomsen, M. F., Yin, L., and Winske, D.: Electromagnetic proton cyclotron instability: Interactions with magnetospheric protons, J. Geophys. Res., 100, 21961-21972, 1995.

Grew, R. S., Menk, F. W., Clilverd, M. A., and Sandel, B. R.: Mass and electron densities in the inner magnetosphere during a prolonged disturbed interval, Geophys. Res. Lett., 34, L02108, doi:10.1029/2006GL028254, 2007.

Gustafsson, G., André, M., Carozzi, T., Eriksson, A. I., Fälthammar, C.-G., Grard, R., Holmgren, G., Holtet, J. A., Ivchenko, N., Karlsson, T., Khotyaintsev, Y., Klimov, S., Laakso, H., Lindqvist, P.-A., Lybekk, B., Marklund, G., Mozer, F., Mursula, K., Pedersen, A., Popielawska, B., Savin, S., Stasiewicz, K., Tanskanen, P., 
Vaivads, A., and Wahlund, J.-E.: First results of electric field and density observations by Cluster EFW based on initial months of operation, Ann. Geophys., 19, 1219-1240, doi:10.5194/angeo19-1219-2001, 2001.

Halford, A. J., Fraser, B. J., and Morley, S. K.: EMIC waves and plasmaspheric and plume density: CRRES results, J. Geophys. Res.-Space, 120, 1974-1992, doi:10.1002/2014JA020338, 2015.

Horne, R. B. and Thorne, R. M.: On the preferred source location for the convective amplification of ion cyclotron waves, J. Geophys. Res., 98, 9233-9247, 1993.

Johnstone, A. D., Alsop, C., Burge, S., Carter P. J., Coates, A. J., Coker. A. J., Fazakerley, A. N., Grande, M., Gowen, R. A., Gurgiolo, C., Hancock, B. K., Narheim, B., Preece, A., Sheather, P. H., Winningham, J. D., and Woodliffe, R. D.: PEACE: A plasma electron and current experiment, Space Sci. Rev., 79, 351-398, doi:10.1023/A:1004938001388, 1997.

Jordanova, V. K., Spasojević, M., and Thomsen, M. F.: Modeling the electromagnetic ion cyclotron wave-induced information of detached subauroral proton arcs, J. Geophys. Res., 112, A08209, doi:10.1029/2006JA012215, 2007.

Kennel, C. F. and Petschek, H. E.: Limit on stably trapped particle fluxes, J. Geophys. Res., 71, 1-28, doi:10.1029/JZ071i001p00001, 1966.

Li, Z., Millan R. M., Hudson, M. K., Woodger, L. A., Smith, D. M., Chen, Y., Friedel, R., Rodriguez, J. V., Engebretson, M. J., Goldstein, J., Fennell, J. F., and Spence, H. E.: Investigation of EMIC wave scattering as the cause for the BARREL 17 January 2013 relativistic electron precipitation event: A quantitative comparison of simulation with observations, Geophys. Res. Lett., 41, 8722-8729, doi:10.1002/2014GL062273, 2014.

Liang, J., Donovan, E., Spanswick, E., and Angelopoulos, V.: Multiprobe estimation of field line curvature radius in the equatorial magnetosphere and the use of proton precipitations in magnetosphere-ionosphere mapping, J. Geophys. Res.-Space, 118, 4924-4945, doi:10.1002/jgra.50454, 2013.

Liang, J., Donovan, E., Ni, B., Yue, C., Jiang, F., and Angelopoulos, V.: On an energy-latitude dispersion pattern of ion precipitation potentially associated with magnetospheric EMIC waves, J. Geophys. Res.-Space, 119, 8137-8160, doi:10.1002/2014JA020226, 2014.

Liu, Y. H., Fraser, B. J., and Menk, F. W.: Pc2 EMIC waves generated high off the equator in the dayside outer magnetosphere, Geophys. Res. Lett., 39, L17102, doi:10.1029/2012GL053082, 2012.

Morley, S. K., Ables, S. T., Sciffer, M. D., and Fraser, B. J.: Multipoint observations of Pc1-2 waves in the afternoon sector, J. Geophys. Res., 114, A09205, doi:10.1029/2009JA014162, 2009.

Pedersen, A., Décréau, P., Escoubet, C.-P., Gustafsson, G., Laakso, H., Lindqvist, P.-A., Lybekk, B., Masson, A., Mozer, F., and Vaivads, A.: Four-point high time resolution information on electron densities by the electric field experiments (EFW) on Cluster, Ann. Geophys., 19, 1483-1489, doi:10.5194/angeo-19-14832001, 2001.

Rème, H., Aoustin, C., Bosqued, J. M., Dandouras, I., Lavraud, B., Sauvaud, J. A., Barthe, A., Bouyssou, J., Camus, Th., Coeur-Joly, O., Cros, A., Cuvilo, J., Ducay, F., Garbarowitz, Y., Medale, J. L., Penou, E., Perrier, H., Romefort, D., Rouzaud, J., Vallat, C., Alcaydé, D., Jacquey, C., Mazelle, C., d'Uston, C., Möbius, E., Kistler, L. M., Crocker, K., Granoff, M., Mouikis, C., Popecki,
M., Vosbury, M., Klecker, B., Hovestadt, D., Kucharek, H., Kuenneth, E., Paschmann, G., Scholer, M., Sckopke, N., Seidenschwang, E., Carlson, C. W., Curtis, D. W., Ingraham, C., Lin, R. P., McFadden, J. P., Parks, G. K., Phan, T., Formisano, V., Amata, E., Bavassano-Cattaneo, M. B., Baldetti, P., Bruno, R., Chionchio, G., Di Lellis, A., Marcucci, M. F., Pallocchia, G., Korth, A., Daly, P. W., Graeve, B., Rosenbauer, H., Vasyliunas, V., McCarthy, M., Wilber, M., Eliasson, L., Lundin, R., Olsen, S., Shelley, E. G., Fuselier, S., Ghielmetti, A. G., Lennartsson, W., Escoubet, C. P., Balsiger, H., Friedel, R., Cao, J.-B., Kovrazhkin, R. A., Papamastorakis, I., Pellat, R., Scudder, J., and Sonnerup, B.: First multispacecraft ion measurements in and near the Earth's magnetosphere with the identical Cluster ion spectrometry (CIS) experiment, Ann. Geophys., 19, 1303-1354, doi:10.5194/angeo19-1303-2001, 2001.

Sakaguchi, K., Shiokawa, K., Miyoshi, Y., Otsuka, Y., Ogawa, T., Asamura, K., and Connors, M.: Simultaneous appearance of isolated auroral arcs and Pc1 geomagnetic pulsations at subauroral latitudes, J. Geophys. Res., 113, A05201, doi:10.1029/2007JA012888, 2008.

Scudder, J. D., Cao, X., and Mozer, F. S.: Photoemission currentspacecraft voltage relation: Key to routine, quantitative lowenergy plasma measurements, J. Geophys. Res., 105, 2128121294, doi:10.1029/1999JA900423, 2000.

Sergeev, V. A., Sazhina, E., Tsyganenko, N., Lundblad, J., and Soraas, F.: Pitch-angle scattering of energetic protons in the magnetotail current sheet as the dominant source of their isotropic precipitation into the nightside ionosphere, Planet. Space Sci., 31, 1147-1155, 1983.

Sibeck, D. G., Mcentire, R. W., Liu, A. T. Y., Lopez, R. E., and Krimigis, S. M.: Magnetic field drift shell splitting: Cause of unusual dayside particle pitch angle distributions during storms and substorms, J. Geophys. Res., 92, 13485-13497, 1987.

Spasojević, M. and Fuselier, S. A.: Temporal evolution of proton precipitation associated with the plasmaspheric plume, J. Geophys. Res., 114, A12201, doi:10.1029/2009JA014530, 2009.

Summers, D. and Thorne, R. M.: Relativistic electron pitchangle scattering by electromagnetic ion cyclotron waves during geomagnetic storms, J. Geophys. Res., 108, 1143, doi:10.1029/2002JA009489, 2003.

Summers, D., Ni, B., and Meredith, N. P.: Timescales for radiation belt electron acceleration and loss due to resonant waveparticle interactions: 1. Theory, J. Geophys. Res., 112, A04206, doi:10.1029/2006JA011801, 2007.

Tsyganenko, N. A. and Sitnov, M. I.: Modeling the dynamics of the inner magnetosphere during strong geomagnetic storms, J. Geophys. Res., 110, A03208, doi:10.1029/2004JA010798, 2005.

Usanova, M. E., Mann, I. R., Kale, Z. C., Rae, I. J., Sydora, R. D., Sandanger, M., Søraas, F., Glassmeier, K.-H., Fornacon, K.-H., Matsui, H., Puhl-Quinn, P. A., Masson, A., and Vallières, X.: Conjugate ground and multisatellite observations of compression-related EMIC Pc1 waves and associated proton precipitation, J. Geophys. Res., 115, A07208, doi:10.1029/2009JA014935, 2010.

Usanova, M. E., Darrouzet, F., Mann, I. R., and Bortnik, J.: Statistical analysis of EMIC waves in plasmaspheric plumes from Cluster observations, J. Geophys. Res.-Space, 118, 4946-4951, doi:10.1002/jgra.50464, 2013. 
Usanova, M. E., Drozdov, A., Orlova, K., Mann, I. R., Shprits, Y., Robertson, M. T., Turner, D. L., Milling, D. K., Kale, A., Baker, D. N., Thaller, S. A., Reeves, G. D., Spence, H. E., Kletzing, C., and Wygant, J.: Effect of EMIC waves on relativistic and ultrarelativistic electron populations: Ground-based and Van Allen Probes observations, Geophys. Res. Lett., 41, 1375-1381, doi:10.1002/2013GL059024, 2014.

Vallat, C., Dandouras, I., Brandt, P. C., DeMajistre, R., Mitchell, D. G., Roelof, E. C., Rème, H., Sauvaud, J.-A., Kistler, L., Mouikis, C., Dunlop, M., and Balogh, A.: First comparisons of local ion measurements in the inner magnetosphere with ENA magnetospheric image inversions: Cluster-CIS and IMAGE-HENA observations, J. Geophys. Res., 109, A04213, doi:10.1029/2003JA010224, 2004.

Volwerk, M., Nakamura, R., Baumjohann, W., Uozumi, T., Yumoto, K., and Balogh, A.: Tailward propagation of Pi2 waves in the Earth's magnetotail lobe, Ann. Geophys., 26, 4023-4030, doi:10.5194/angeo-26-4023-2008, 2008.

Wang, Z., Yuan, Z., Li, M., Li, H., Wang, D., Li, H., Huang, S., and Qiao, Z.: Statistical characteristics of EMIC wave driven relativistic electron precipitation with observations of POES satellites: Revisit, J. Geophys. Res.-Space, 119, 5509-5519, doi:10.1002/2014JA020082, 2014.

Williams, D. J.: Ring current and radiations belts, Rev. Geophys., 25, 570-578, doi:10.1029/RG025i003p00570, 1987.

Yahnin, A. G. and Yahnina, T. A.: Energetic proton precipitation related to ion-cyclotron waves, J. Atmos. Terr. Phys., 69, 16901706, 2007.

Yahnin, A. G., Yahnina, T. A., Ganushkina, N. Y., Angelopoulos, V., Mozer, F. S., Kangas, J., Manninen, J., Fritz, T. A., and Russell, C. T.: Multi-satellite study of phenomena in the evening magnetosphere during the Pc1-2 event, in: Proceedings of XXV Apatity Seminar "Physics of Auroral Phenomena", Apatity, Russia, 8588, 2002.

Yahnin, A. G., Yahnina, T. A., and Demekhov, A. G.: Interrelation between localized energetic particle precipitation and cold plasma inhomogeneities in the magnetosphere, Geomagn. and Aeronomy+, 46, 332-338, 2006.
Yahnin, A. G., Yahnina, T. A., Frey, H. U., Bösinger, T., and Manninen, J.: Proton aurora related to intervals of pulsations of diminishing periods, J. Geophys. Res., 114, A12215, doi:10.1029/2009JA014670, 2009.

Young, D. T., Perraut, S., Roux, A., de Villedary, C., Gendrin, R., Korth, A. Kremser, G., and Jones, D.: Wave-particle interactions near observed on GEOS 1 and 21 . Propagation of ion cyclotron waves in He+ rich plasma, J. Geophys. Res., 86, 6755-6772, 1981.

Yuan, Z., Deng, X., Lin, X., Pang, Y., Zhou, M., Décréau, P. M. E., Trotignon, J. G., Lucek, E., Frey, H. U., and Wang, J.: Link between EMIC waves in a plasmaspheric plume and a detached sub-auroral proton arc with observations of Cluster and IMAGE satellites, Geophys. Res. Lett., 37, L07108, doi:10.1029/2010GL042711, 2010.

Yuan, Z., Xiong, Y., Pang, Y., Zhou, M., Deng, X., Trotignon, J. G., Lucek, E., and Wang, J.: Wave-particle interaction in a plasmaspheric plume observed by a Cluster satellite, J. Geophys. Res., 117, A03205, doi:10.1029/2011JA017152, 2012a.

Yuan, Z., Xiong, Y., Wang, D., Li, M., Deng, X., Yahnin, A. G., Raita, T., and Wang, J.: Characteristics of precipitating energetic ions/electrons associated with the wave-particle interaction in the plasmaspheric plume, J. Geophys. Res., 117, A08324, doi:10.1029/2012JA017783, 2012b.

Yuan, Z., Li, M., Xiong, Y., Li, H., Zhou, M., Wang, D., Huang, S., Deng, X., and Wang, J.: Simultaneous observations of precipitating radiation belt electrons and ring current ions associated with the plasmaspheric plume, J. Geophys. Res.-Space, 118, 43914399, doi:10.1002/jgra.50432, 2013.

Yuan, Z., Xiong, Y., Li, H., Huang, S., Qiao, Z., Wang, Z., Zhou, M., Wang, D., Deng, X., Raita, T., and Wang, J.: Influence of precipitating energetic ions caused by EMIC waves on the subauroral ionospheric $\mathrm{E}$ region during a geomagnetic storm, J. Geophys. Res.-Space, 119, 8462-8471, doi:10.1002/2014JA020303, 2014 